Check for updates

Cite this: RSC Adv., 2020, 10, 31819

Received 31st July 2020

Accepted 21st August 2020

DOI: $10.1039 / \mathrm{d} 0 \mathrm{ra06635d}$

rsc.li/rsc-advances

\title{
Regioselective $\mathrm{C}-\mathrm{H}$ sulfenylation of $\mathrm{N}$-sulfonyl protected 7-azaindoles promoted by TBAI: a rapid synthesis of 3-thio-7-azaindoles $\uparrow$
}

\author{
Jingyan $\mathrm{Hu}{ }^{a}$ Xiaoming $\mathrm{Ji},{ }^{* a}$ Shuai Hao, ${ }^{a}$ Mingqin Zhao, ${ }^{a}$ Miao Lai, ${ }^{a}$ Tianbao Ren, ${ }^{a}$ \\ Gaolei Xi, ${ }^{\mathrm{b}}$ Erbin Wang, ${ }^{\mathrm{b}}$ Juanjuan Wang ${ }^{\mathrm{b}}$ and Zhiyong Wu iD *a
}

\begin{abstract}
This paper describes the regioselective $\mathrm{C}$ - 3 sulfenylation of $\mathrm{N}$-sulfonyl protected 7 -azaindoles with sulfonyl chlorides. In this transformation, dual roles of TBAI serving as both promoter and desulfonylation reagent have been demonstrated. The reaction proceeded smoothly under simple conditions to afford 3-thio-7azaindoles in moderate to good yields with broad substrate scopes. This protocol refrains from using transition-metal catalysts, strong oxidants or bases, and shows its practical synthetic value in organic synthesis.
\end{abstract}

\section{Introduction}

Indole core structures are the most important nitrogencontaining aromatic heterocycles, which are widely distributed in organic synthesis, ${ }^{\mathbf{1}}$ medicinal chemistry, ${ }^{2}$ natural products, ${ }^{3}$ pharmaceutical agents, ${ }^{4}$ and others. ${ }^{5}$ Among them, 7azaindoles and their synthetic analogues which possess the same [4.3]-bicyclic indene architecture as indoles (Fig. 1), have become one of the most widely studied organic templates, in part probably because of their prevalence in many bio-active structures $^{6}$ and functional molecules ${ }^{7}$ (Fig. 1a-c).

Due to the significance of such sub-structures in various fields, chemists are showing an increased interest in developing effective methods to form 7 -azaindole derivatives. ${ }^{8}$ Traditionally, 7-azaindole derivatives are synthesized starting from aminopyridines through the construction of pyrrole ring. ${ }^{\mathbf{8 a}, \boldsymbol{b}, \mathbf{9}}$ However, these methodologies suffer from some drawbacks such as toxic and foul-smelling reagents, prolonged reaction steps and low atom efficiency, which limit their wide applications. With the aim to functionalize the 7-azaindoles in a mild and atom-economical manner, transition-metal catalyzed $\mathrm{C}-\mathrm{H}$ bonds activation has been described as an attractive strategy (Scheme 1a). ${ }^{\mathbf{1 0}}$ For example, Sames, ${ }^{\mathbf{1 1}}$ Fagnou, ${ }^{\mathbf{1 2}}$ DeBoef, ${ }^{13}$ Das, ${ }^{\mathbf{1 4}}$ Cao, ${ }^{15}$ and Laha $^{16}$ reported independently the palladiumcatalyzed C-2 arylation of 7-azaindole by using aryl iodide or

${ }^{a}$ Flavors and Fragrance Engineering \& Technology Research Center of Henan Province, College of Tobacco Science, Henan Agricultural University, Zhengzhou, 450002, China. E-mail: xiaomingji@henau.edu.cn; smileyongyong062@163.com

${ }^{b}$ Technology Center, China Tobacco Henan Industrial Co., Ltd., Zhengzhou, Henan, 450000, China

$\dagger$ Electronic supplementary information (ESI) available. CCDC 2018442. For ESI and crystallographic data in CIF or other electronic format see DOI: 10.1039/d0ra06635d benzene as coupling partners under different conditions. In addition, the $\mathrm{N}$-oxide-assisted palladium-catalyzed $\mathrm{C} 6-\mathrm{H}$ arylation of 7-azaindoles has also been achieved by Fagnou and coworkers. ${ }^{12}$ Das's group ${ }^{17}$ realized the oxidative $\mathrm{C} 3-\mathrm{H}$ alkenylation of 7-azaindoles under palladium catalysis. However, the use of transition-metals may cause potential contamination of the products, which is particularly significant in the pharmaceutical industry and advanced functional materials. Among others, the $\mathrm{C}-\mathrm{H}$ bonds activation reaction under transitionmetal-free conditions has emerged as promising protocols

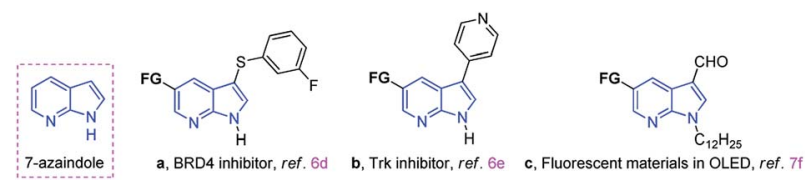

Fig. 1 Biological activity and material applications of 7-azaindole derivatives.

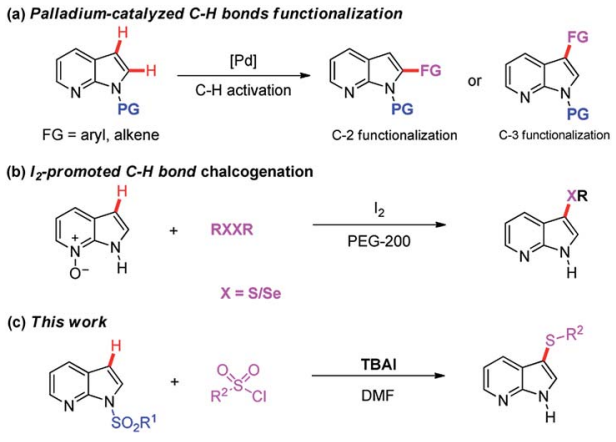

Scheme 1 Regioseletive $\mathrm{C}-\mathrm{H}$ functionalization of 7-azaindoles. 
because of their environmental friendliness. For instance, $\mathrm{Liu}^{\mathbf{1 8}}$ and co-workers developed a regioselective deoxygenative $\mathrm{C}-\mathrm{H}$ thiolation of 7 -azaindole $\mathrm{N}$-oxides with $\mathrm{I}_{2} / \mathrm{PEG}$ as the efficient and reusable catalytic system (Scheme 1b). Some other specific examples on C-3 sulfenylation of free 7-azaindole have also been achieved by Zhang, ${ }^{19}$ Wang, $^{20}$ Liu $^{21}$ and Sinha. ${ }^{22}$ Despite this progress, direct C-3 sulfenylation of $\mathrm{N}$-sulfonyl protected 7azaindoles using TBAI (tetrabutylammonium iodide) both as the promoter and as the desulfonylation reagent has not yet been documented. Based on our ongoing interest in the formation of $\mathrm{C}-\mathrm{S}$ bond, ${ }^{23}$ herein, we want to disclose the regioselective $\mathrm{C}-\mathrm{H}$ bond sulfenylation of $\mathrm{N}$-sulfonyl protected 7azaindoles promoted by TBAI (Scheme 1c).

\section{Results and discussion}

At the outset of this investigation, we commenced our study on the model reaction of $N$-Ts protected 7-azaindole (1a) with tosyl chloride (2a) to optimize various reaction parameters. The results were summarized in Table 1 . Initially, C-3 sulfenylation took place in the presence of TBAI (3 equiv.) in DMF under air, affording product $3 \mathbf{a}$ in $35 \%$ yield (entry 1, Table 1). The molecular structure of 3a was confirmed by NMR and HRMS spectra. Inspired by this result, various additives such as NaI, KI, $\mathrm{I}_{2}$ and TBAB were screened (entries 2-5, Table 1 ), however, no better results were observed with these experiments. The effect of solvent was also examined, and the results showed that DMAc gave lower yield of $3 \mathbf{a}$ (entry $6 v$ s. entry 1 , Table 1 ) while no

Table 1 Optimization of the reaction conditions ${ }^{a}$

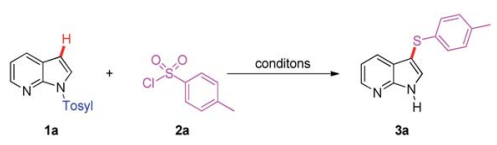

\begin{tabular}{llll}
\hline Entry & Additive & Solvent & Yield $^{b}(\%)$ \\
\hline 1 & TBAI & DMF & 35 \\
2 & NaI & DMF & 17 \\
3 & KI & DMF & 14 \\
4 & I & DMF & N.R. \\
5 & TBAB & DMF & N.R. \\
6 & TBAI & DMAc & 23 \\
7 & TBAI & $1,4-$ Dioxane & N.R. \\
8 & TBAI & Acetonitrile & N.R. \\
9 & TBAI & Toluene & N.R. \\
10 & TBAI & DCE & N.R. \\
$11^{c}$ & TBAI & DMF & 72 \\
$12^{d}$ & TBAI & DMF & 79 \\
$13^{e}$ & TBAI & DMF & 82 \\
$14^{d, f}$ & TBAI & DMF & 84 \\
$15^{d, g}$ & TBAI & DMF & 86 \\
$16^{d, h}$ & TBAI & DBA & 80 \\
$17^{d, g, i}$ & TBAI & DMF & 83
\end{tabular}

${ }^{a}$ Reaction conditions: 1a $(0.15 \mathrm{mmol}), 2 \mathrm{a}(0.45 \mathrm{mmol})$, additive $(3.0$ equiv.) and solvent $(1 \mathrm{~mL}), 80^{\circ} \mathrm{C}, 18 \mathrm{~h} .{ }^{b}$ Isolated yields. ${ }^{c}$ Run at 100 ${ }^{\circ} \mathrm{C}$. ${ }^{d}$ Run at $120{ }^{\circ} \mathrm{C}$. ${ }^{e}$ Run at $140{ }^{\circ} \mathrm{C}$. ${ }^{f}$ Run for 12 h. ${ }^{g}$ Run for $6 \mathrm{~h}$. ${ }^{h}$ Run for 3 h. ${ }^{i}$ Run under $\mathrm{N}_{2}$ atmosphere. N.R. = no reaction. desired product was observed with 1,4-dioxane, acetonitrile, toluene and DCE (entries 7-10, Table 1). Gratifyingly, increasing the reaction temperature resulted in a significant improving of the product yield (entries 11-13, Table 1) and the highest yield (79\%) product 3a was observed when the reaction was conducted at $120^{\circ} \mathrm{C}$ for $18 \mathrm{~h}$. The reaction time was also examined (entries 14 and 15, Table 1), and $6 \mathrm{~h}$ was found to be the best choice. The nitrogen protected reaction was also carried out, and a similar result was obtained in this reaction compared with the reaction in air (entry 17 vs. entry 15, 83\% vs. 86\%, Table 1). Based on the detailed investigations, we confirmed that the optimal conditions: TBAI (3.0 equiv.) as the additive in DMF at $120{ }^{\circ} \mathrm{C}$ under air atmosphere for $6 \mathrm{~h}$ (entry 15, Table 1 ).

Based on the optimized conditions presented above, we subsequently focused on examining the generality and limitations of this protocol (Tables 2 and 3). Firstly, various protecting groups were surveyed for this transformation, and the results were summarized in Table 2. Both aryl sulfonyl and alkyl sulfonyl protected 7-azaindole underwent the reaction smoothly to provide the corresponding products in moderate to good yields (3a-1-6, 54-86\%, Table 2). Generally, different type of protecting groups have some appreciable influence on the outcome of the reaction, and tosyl group was confirmed as the best one. Next, a wide range of substituted aryl sulfonyl chlorides was subjected to the reaction with $N$-Ts protected 7 -azaindole (1a) to produce

Table 2 Substrate scope of protecting groups and sulfonyl chlorides for the sulfenylation reactions $s^{a, b, c}$

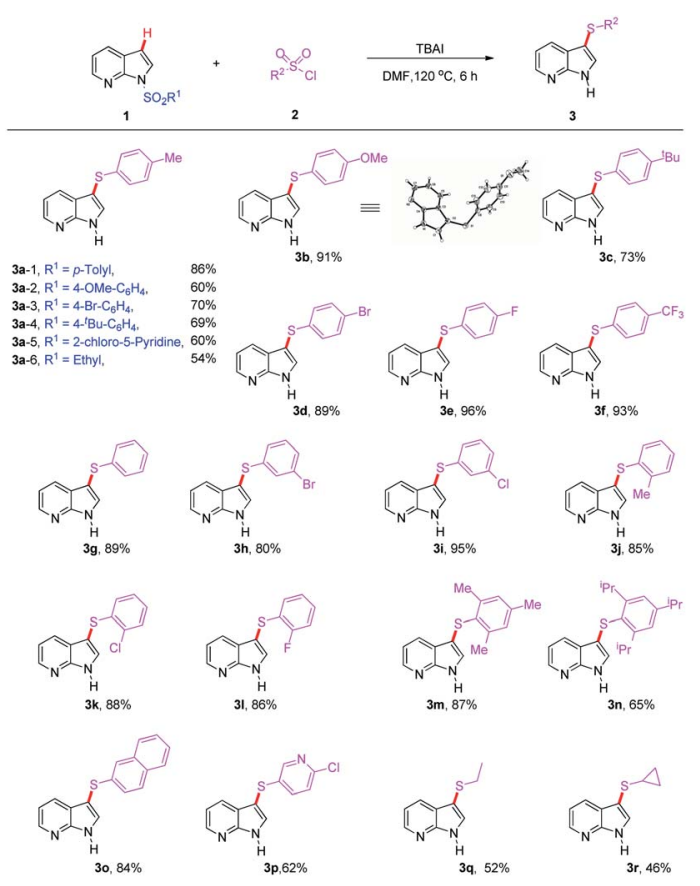

${ }^{a}$ Reaction conditions: $1(0.15 \mathrm{mmol}), 2(0.45 \mathrm{mmol})$, TBAI $(3$ equiv. $)$,
DMF $1 \mathrm{~mL}, 120^{\circ} \mathrm{C}, 6 \mathrm{~h}$, under air. ${ }^{b}$ Isolated yields. ${ }^{c} \mathrm{R}^{1}=p$-tolyl for products $\mathbf{3 b}-\mathbf{3 r}$. 
Table 3 Substrate scope of $N$-Ts protected 7-azaindoles for the sulfenylation reactions ${ }^{a, b}$

the corresponding product $\mathbf{3 b} \mathbf{b}-\mathbf{3 n}$ in moderate to good yields (6596\%). Notably, benzenesulfonyl chloride and the monosubstituted (Me, OMe, $t$-Bu) benzenesulfonyl chlorides have proven to be suitable substrates for the reaction to provide the corresponding products $(\mathbf{3 b}-\mathbf{c}, \mathbf{3} \mathbf{g}$ and $\mathbf{3} \mathbf{j})$ in synthetic acceptable yields (73-91\%). Substrates bearing electron-withdrawing substituents also resulted in good yields. Halides such as $\mathrm{F}, \mathrm{Cl}$, and $\mathrm{Br}$ afforded the desired products in $80-96 \%$ yields (3d-e, $3 \mathbf{3 h}-$ i, 3k-1), even strong electron-withdrawing groups $\left(\mathrm{CF}_{3}\right)$ gave quite good yield of $\mathbf{3 f}$ (93\%). Aryl sulfonyl chlorides containing a sterically hindered groups, bicyclic moiety naphthalene and substituted pyridine ring showed good compatibility (3m-p, 62$87 \%)$. Ethanesulfonyl chloride and cyclopropanesulfonyl chloride reacted as well to give the desired products $\mathbf{3 q}$ and $\mathbf{3 r}$ with yields of $52 \%$ and $46 \%$, respectively. These results greatly expanded the substrate scope of this reaction.

The compatibility of 7-azaindole derivatives was subsequently evaluated in this transformation (Table 3). Not surprisingly, the reaction of substrate 2 a with several substituted $N$-Ts protected 7-azaindoles furnished the corresponding products $(\mathbf{4 a - d})$ in moderate yields. It is noteworthy that although relatively low yields were obtained when the halogenated 7-azaindoles were subjected to the reaction, it may provide a significant opportunity for their further transformation by transition-metal-catalyzed coupling reactions, especially in pharmacological demand.

Considering the experimental results and previously reports, ${ }^{24}$ a plausible mechanism was proposed and illustrated in Scheme 2. We envisioned that the formation of sulfonyl iodide A by anion exchange of sulfonyl chloride and TBAI would be the initial step of this transformation. Then, sulfonyl iodide $\mathrm{A}$ is continuously reduced into the intermediates $\mathrm{B},{ }^{21,25}$ which undergoes homolytic cleavage to produce the active sulfur radical C. ${ }^{24 a}$ Subsequently, the addition of sulfur radical to 7azaindole occurs chemoselectively and generates a key intermediate $\mathrm{D}$, which captured by the iodine radical from intermediates B affording intermediate E. Next, HI elimination takes place to provide 3-thio-7-azaindole $\mathrm{F}$, which readily undergoes $N$-desulfonylation ${ }^{\mathbf{1 6 a , 2 6}}$ to provide the desired products 3 .

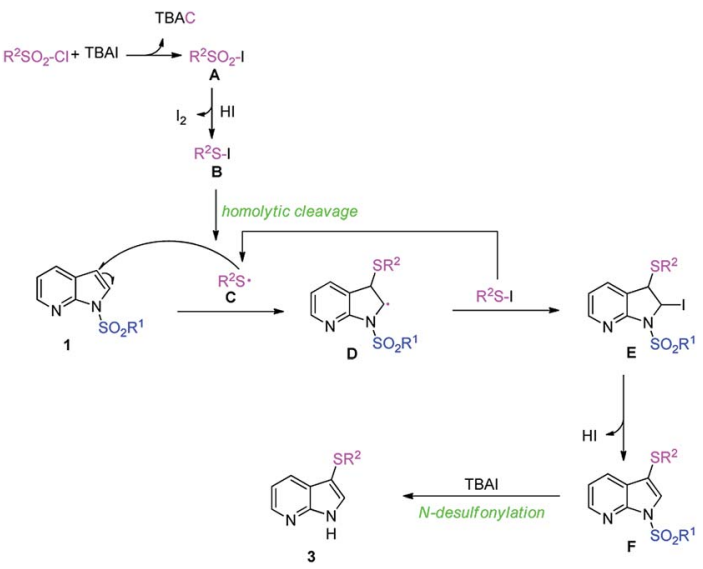

Scheme 2 Plausible reaction mechanism.

\section{Conclusions}

In summary, we have described an efficient approach for the production of 3-thio-7-azaindoles via $\mathrm{C}-\mathrm{H}$ bond activation under transition-metal-free conditions. In this protocol, dual roles of TBAI serving as both promoter and desulfonylation reagent have been demonstrated, and a series of 3-thio-7azaindoles were obtained in moderate to good yields with high regioselectivity and good functional group tolerance. Further studies on extending the substrate scope and the application of the obtained products are underway, and the results will be forthcoming soon.

\section{Conflicts of interest}

There are no conflicts to declare.

\section{Acknowledgements}

The authors greatly acknowledge the financial support by The Education Department of Henan Province (20A210023), Henan Agricultural University (30500567, 30500701) and Key Science and the Technology Program of Science and Technology Department of Henan Province (152102210058, 122102210129).

\section{Notes and references}

1 (a) C. M. So, C. C. Yeung, C. P. Lau and F. Y. Kwong, A new family of tunable indolylphosphine ligands by one-pot assembly and their applications in suzuki-miyaura coupling of aryl chlorides, J. Org. Chem., 2008, 73, 78037806; (b) L. Chen and Y. Zou, Recent progress in the synthesis of phosphorus-containing indole derivatives, Org. Biomol. Chem., 2018, 16, 7544-7556.

2 (a) M. Zhang, Q. Chen and G. Yang, A review on recent developments of indole-containing antiviral agents, Eur. J. Med. Chem., 2015, 89, 421-441; (b) T. P. Singh and O. M. Singh, Recent progress in biological activities of indole and indole alkaloids, Mini-Rev. Med. Chem., 2018, 18, 9-25; (c) S. Suzen, Recent studies and biological aspects 
of substantial indole derivatives with anti-cancer activity, Curr. Org. Chem., 2017, 21, 2068-2076; (d) S. M. Li, Prenylated indole derivatives from fungi: structure diversity, biological activities, biosynthesis and chemoenzymatic synthesis, Nat. Prod. Rep., 2010, 27, 57-78.

3 (a) S. R. Walker, E. J. Carter, B. C. Huff and J. C. Morris, Variolins and related alkaloids, Chem. Rev., 2009, 109, 3080-3098; (b) A. J. Kochanowska-Karamyan and M. T. Hamann, Marine indole alkaloids: potential new drug leads for the control of depression and anxiety, Chem. Rev., 2010, 110, 4489-4497; (c) R. J. Melander, M. L. Minvielle and C. Melander, Controlling bacterial behavior with indole-containing natural products and derivatives, Tetrahedron, 2014, 70, 6363-6372; (d) Y. Ma, X. Liang, Y. Kong and B. Jia, Structural diversity and biological activities of indole diketopiperazine alkaloids from fungi, J. Agric. Food Chem., 2016, 64, 6659-6671.

4 (a) C. Gerhauer, M. You, J. Liu, R. M. Moriarty, M. Hawthorne, R. G. Mehta, R. C. Moon and J. M. Pezzuto, Cancer chemopreventive potential of sulforamate, a novel analogue of sulforaphane that induces phase II drugmetabolizing enzymes, Cancer Res., 1997, 57, 272-278; (b) C. Sherer and T. J. Snape, Heterocyclic Scaffolds as promising anticancer agents against tumours of the central nervous system: exploring the scope of indole and carbazole derivatives, Eur. J. Med. Chem., 2015, 97, 552560; (c) F. R. de Sa Alves, E. J. Barreiro and C. A. M. Fraga, From nature to drug discovery: the indole scaffold as a 'privileged structure', Mini-Rev. Med. Chem., 2009, 9, 782793.

5 (a) Z. R. Owczarczyk, W. A. Braunecker, A. Garcia, R. Larsen, A. M. Nardes, N. Kopidakis, D. S. Ginley and D. C. Olson, 5,10-Dihydroindolo[3,2-b]indole-based copolymers with alternating donor and acceptor moieties for organic photovoltaics, Macromolecules, 2013, 46, 1350-1360; (b) G. Nie, Z. Bai, W. Yu and L. Zhang, Electrochemiluminescence biosensor for ramos cells based on a nanostructured conducting polymer composite material (PICA-MWNTs), J. Polym. Sci., Part A: Polym. Chem., 2013, 51, 2385-2392; (c) M. Manickam, P. Iqbal, M. Belloni, S. Kumar and J. A. Preece, A brief review of carbazole-based photorefractive liquid crystalline materials, Isr. J. Chem., 2012, 52, 917-934.

6 (a) A. A. Prokopov and L. N. Yakhontov, Chemistry of the azaindoles, Pharm. Chem. J., 1994, 28, 471-506; (b) T. Irie and M. Sawa, 7-Azaindole: a versatile scaffold for developing kinase inhibitors, Chem. Pharm. Bull., 2018, 66, 29-36; (c) X. Chen, Z. Jin, Y. Gong, N. Zhao, X. Wang, Y. Ran, Y. Zhang, L. Zhang and Y. Li, 5-HT6 receptor agonist and memory-enhancing properties of hypidone hydrochloride (YL-0919), a novel 5-HT1A receptor partial agonist and SSRI, Neuropharmacology, 2018, 138, 1-9; (d) J. Zhang, J. Buell, K. Chan, P. N. Ibrahim, J. Lin, P. Pham, S. Shi, W. Spevak, G. Wu and J. Wu, Preparation of heterocyclic compounds as BRD4 inhibitors and uses thereof PCT, Int. Appl., WO2014145051A120140918, 2014; (e) T.-T. Jaana, P. Rahel, J. Kaur, L. Kristi, D. A. Dobchev,
D. Kananovich, A. Noole, M. Mandel, A. Kaasik, M. Lopp, T. Timmusk and M. Karelson, Indole-like trk receptor antagonists, Euro. J. Med. Chem., 2016, 121, 541-552; $(f)$ S. Hong, J. Kim, J. H. Seo, K. H. Jung, S. Hong and S. Hong, Design, synthesis, and evaluation of 3, 5disubstituted 7-azaindoles as trk inhibitors with anticancer and antiangiogenic activities, J. Med. Chem., 2012, 55, 5337-5349.

7 For reviews, see: (a) Y. Wu, H. Huang, J. Shen, H. Tseng, J. Ho, Y. Chen and P. Chou, Water-catalyzed excited-state proton-transfer reactions in 7-azaindole and its analogues, J. Phys. Chem. B, 2015, 119, 2302-2309; (b) T. Tu, Y. Chen, J. Shen, T. Lin and P. Chou, Excited-state proton transfer in 3-cyano-7-azaindole: from aqueous solution to ice, $J$. Phys. Chem. A, 2018, 122, 2479-2484; (c) S. Zhao and S. Wang, Luminescence and reactivity of 7-azaindole derivatives and complexes, Chem. Soc. Rev., 2010, 39, 31423156. For selected examples, see: (d) K. Kaur, S. Chaudhary, S. Singh and S. K. Mehta, An azaindolehydrazine imine moiety as sensitive dual cation chemosensor depending on surface plasmon resonance and emission properties, Sens. Actuators, 2016, 222, 397406; (e) C. Martín, K. Kennes, M. Van der Auweraer, J. Hofkens, G. de Miguel and E. M. García-Frutos, Self-assembling azaindole organogel for organic light-emitting devices (OLEDs), Adv. Funct. Mater., 2017, 27, 1702176; (f) C. Martin, C. Borreguero, K. Kennes, M. Van der Auweraer, J. Hofkens, G. de Miguel and E. M. Garciá-Frutos, Simple donor-acceptor luminogen based on an azaindole derivative as solid-state emitter for organic light-emitting devices, ACS Energy Lett., 2017, 2, 2653-2658.

8 (a) J. J. Song, J. T. Reeves, F. Gallou, Z. Tan, N. K. Yee and C. H. Senanayake, Organometallic methods for the synthesis and functionalization of azaindoles, Chem. Soc. Rev., 2007, 36, 1120-1132; (b) A. Sofia Santos, A. C. Mortinho and M. M. B. Marques, Metal-catalyzed cross-coupling reactions on azaindole synthesis and functionalization, metal-catalyzed cross-coupling reactions on azaindole synthesis and functionalization, Molecules, 2018, 23, 2673; (c) W.-H. Zhong, Y. Zhong, H. Mao and $\mathrm{X}$. Chao, Recent progress on the synthesis of (aza)indoles through oxidative alkyne annulation reactions, Synlett, 2017, 15, 1867-1872.

9 (a) M. J. D. Pires, D. L. Poeira and M. M. B. Marques, Metalcatalyzed cross-coupling reactions of aminopyridines, Eur. J. Org. Chem., 2015, 2015, 7197-7234; (b) J. Merour, S. Routier, F. Suzenet and B. Joseph, Recent advances in the synthesis and properties of 4-, 5-, 6-or 7-azaindoles, Tetrahedron, 2013, 69, 4767-4834.

10 (a) J. M. Lopchuk, Five-Membered Ring Systems: Pyrroles and Benzo Analogs, in Progress in Heterocyclic Chemistry, ed. G. Gribble and J. J. Joule, Elsevier, Oxford, 2017, vol. 29, pp. 183-238; (b) L. Ouyang and W. Wu, Recent advancements in palladium-catalyzed reactions involving molecular oxygen, Curr. Opin. Green Sustain. Chem., 2017, 
7, 46-55; (c) M. Petrini, Regioselective direct C-alkenylation of indoles, Chem.-Eur. J., 2017, 64, 16115-16151.

11 (a) B. S. Lane and D. Sames, Direct $\mathrm{C}-\mathrm{H}$ bond arylation: selective palladium-catalyzed c2-arylation of $\mathrm{N}$-substituted indoles, Org. Lett., 2004, 6, 2897-2900; (b) B. S. Lane, M. A. Brown and D. Sames, Direct palladium-catalyzed C-2 and C-3 arylation of indoles: a mechanistic rationale for regioselectivity, J. Am. Chem. Soc., 2005, 127, 8050-8057.

12 M. P. Huestis and K. Fagnou, Site-selective azaindole arylation at the azine and azole rings via n-oxide activation, Org. Lett., 2009, 11, 1357-1360.

13 S. Potavathri, K. C. Preira, S. I. Gorelsky, A. Pike, A. P. Lebris and B. DeBoef, Regioselective oxidative arylation of indoles bearing $n$-alkyl protecting groups: dual $\mathrm{c}-\mathrm{h}$ functionalization via a concerted metalation-deprotonation mechanism, J. Am. Chem. Soc., 2010, 132, 14676-14681.

14 P. Kannaboina, K. Anilkumar, S. Aravinda, R. A. Vishwakarma and P. Das, Direct C-2 arylation of 7azaindoles: chemoselective access to multiarylated derivatives, Org. Lett., 2013, 15, 5718-5721.

15 (a) Y. Huang, Z. Lin and R. Cao, Palladium nanoparticles encapsulated in a metal-organic framework as efficient heterogeneous catalysts for direct $\mathrm{c} 2$ arylation of indoles, Chem.-Eur. J., 2011, 17, 12706-12712; (b) Y. Huang, T. Ma, P. Huang, D. Wu, Z. Lin and R. Cao, Direct C-H bond arylation of indoles with aryl boronic acids catalyzed by palladium nanoparticles encapsulated in mesoporous metal-organic framework, ChemCatChem, 2013, 5, 18771883.

16 (a) J. K. Laha, R. A. Bhimpuria, D. Prajapati, N. Dayal and S. Sharma, Palladium-catalyzed regioselective c-2 arylation of 7-azaindoles, indoles, and pyrroles with arenes, Chem. Commun., 2016, 52, 4329-4332; (b) J. K. Laha, R. A. Bhimpuria and M. K. Hunjan, Intramolecular oxidative arylations in 7-azaindoles and pyrroles: revamping the synthesis of fused $N$-heterocycle tethered fluorenes, Chem.-Eur. J., 2017, 23, 2044-2050.

17 P. Kannaboina, K. A. Kumar and P. Das, Site-selective intermolecular oxidative c-3 alkenylation of 7-azaindoles at room temperature, Org. Lett., 2016, 18, 900.

18 S. Liu, H. Yang, L. Jiao, J. Zhang, C. Zhao, Y. Ma and X. Yang, Regioselective Deoxygenative Chalcogenation of 7-Azaindole $\mathrm{N}$-Oxides Promoted by $\mathrm{I}_{2} /$ PEG-200, Org. Biomol. Chem., 2019, 17, 10073.

19 P. Sang, Z. Chen, J. Zou and Y. Zhang, $\mathrm{K}_{2} \mathrm{CO}_{3}$ Promoted Direct Sulfenylation of Indoles: a Facile Approach towards 3-Sulfenylindoles, Green Chem., 2013, 15, 2096-2100.

20 H. Zhang, X. Bao, Y. Song, J. Qu and B. Wang, Iodinecatalysed versatile sulfenylation of indoles with thiophenols: controllable synthesis of mono- and bisarylthioindoles, Tetrahedron, 2015, 71, 8885-8891.

21 L. Chen, Y. Wei, Z. Yang, P. Liu, J. Zhang and B. Dai, $\mathrm{NH}_{4} \mathrm{I} /$ 1,10-Phenanthroline catalyzed direct sulfenylation of $\mathrm{N}$ heteroarenes with ethyl arylsulfinates, Tetrahedron, 2015, 71, 8885-8891.
22 D. Equbal, R. Singh, Saima, A. G. Lavekar and A. K. Sinha, Synergistic dual role of $[\mathrm{hmim}] \mathrm{Br}-\mathrm{ArSO} 2 \mathrm{Cl}$ in cascade sulfenylation-halogenation of indole: mechanistic insight into regioselective $\mathrm{C}-\mathrm{S}$ and $\mathrm{C}-\mathrm{S} / \mathrm{C}-\mathrm{X}(\mathrm{X}=\mathrm{Cl}$ and $\mathrm{Br})$ bond formation in one pot, J. Org. Chem., 2019, 84, 2660-2675.

23 (a) Z. Wu, H. Song, X. Cui, C. Pi, W. Du and Y. Wu, Sulfonylation of Quinoline $N$-Oxides with aryl sulfonyl chlorides via copper-catalyzed $\mathrm{C}-\mathrm{H}$ bonds activation, Org. Lett., 2013, 15, 1270-1273; (b) M. Lai, K. Zhai, C. Cheng, $\mathrm{Z}$. $\mathrm{Wu}$ and $\mathrm{M}$. Zhao, Direct thiolation of AzaHeteroaromatic $N$-oxides with disulfides via coppercatalyzed regioselective $\mathrm{C}-\mathrm{H}$ bond activation, Org. Chem. Front., 2018, 5, 2986-2991; (c) Z. Wu, M. Lai, S. Zhang, X. Zhong, H. Song and M. Zhao, An efficient synthesis of benzyl dithiocarbamates by base-promoted cross-coupling reactions of benzyl chlorides with tetraalkylthiuram disulfides at room temperature, Eur. J. Org. Chem., 2018, 2018, 7033-7036; (d) M. Lai, Z. Wu, Y. Wang, Y. Zheng and M. Zhao, Selective synthesis of aryl thioamides and aryl- $\alpha$ ketoamides from $\alpha$-oxocarboxylic acids and tetraalkylthiuram disulfides: an unexpected chemoselectivity from aryl sulfonyl chlorides, Org. Chem. Front., 2019, 6, 506-511; (e) C. Cheng, M. Zhao, M. Lai, K. Zhai, B. Shi, S. Wang, R. Luo, L. Zhang and Z. Wu, Synthesis of aza-heteroaromatic dithiocarbamates via cross-coupling reactions of aza-heteroaromatic bromides with tetraalkylthiuram disulfides, Eur. J. Org. Chem., 2019, 2019, 2941-2949.

24 (a) P. Katrun, C. Mueangkaew, M. Pohmakotr, V. Reutrakul, T. Jaipetch, D. Soorukram and C. Kuhakarn, Regioselective C2 sulfonylation of indoles mediated by molecular iodine, J. Org. Chem., 2014, 79, 1778-1785; (b) W. Fu, K. Sun, C. Qu, X. Chen, L. Qu, W. Bi and Y. Zhao, Iodine-mediated sulfonylation of quinoline $n$-oxides: a mild and metal-free on-pot synthesis of 2-sulfonyl quinolines, Asian J. Org. Chem., 2017, 6, 492-495; (c) F. Xiao, H. Chen, H. Xie, S. Chen, L. Yang and G. Deng, Iodine-catalyzed regioselective 2-sulfonylation of indoles with sodium sulfinates, Org. Lett., 2014, 16, 50-53; (d) J. Zhang, Z. Wang, L. Chen, Y. Liu, P. Liu and B. Dai, The fast and efficient $\mathrm{KI} / \mathrm{H}_{2} \mathrm{O}_{2}$ mediated 2-sulfonylation of indoles and $N$-methylpyrrole in water, $R S C A d v ., 2018,8,41651-41656$.

$25 \mathrm{~S}$. Oae and H. Togo, Reduction of organic sulfonic acids, sodium sulfonates, and sulfonic esters to the corresponding disulfides with polyphosphoric acid derivatives, potassium iodide and the tetrabutylammonium iodids system, Bull. Chem. Soc. Jpn., 1983, 56, 3813-3817.

26 (a) A. Yasuhara and T. Sakamoto, Deprotection of $N$-sulfonyl nitrogen-heteroaromatics with tetrabutylammonium fluoride, Tetrahedron Lett., 1998, 39, 595-596; (b) A. Yasuhara, M. Kameda and T. Sakamoto, Selective monodesulfonylation of $\mathrm{N}, \mathrm{N}$-disulfonylarylamines with tetrabutylammonium fluoride, Chem. Pharm. Bull., 1999, 47, 809-812; (c) Y. Liu, L. Shen, M. Prashad, J. Tibbatts, O. Repic and T. J. Blacklock, A green $N$-detosylation of indoles and related heterocycles using phase transfer catalysis, Org. Process Res. Dev., 2008, 12, 778-780. 